\section{Interspecific Analysis of Xylem Freezing Responses in Acer and Betula}

\author{
Stephanie Byard \\ Division of Plant and Soil Sciences, West Virginia University, Morgantown, \\ WV 26506-6108
}

Michael Wisniewski

U.S. Department of Agriculture, Agriculture Research Service, Appalachian Fruit Research Station, 2217 Wiltshire Road, Kearneysville, WV 25430

\author{
Jianhua Li \\ Arnold Arboretum, Harvard University, Boston, MA 02130 \\ Dale Karlson ${ }^{\mathbf{1 , 2}}$ \\ Division of Plant and Soil Sciences, West Virginia University, Morgantown, \\ WV 26506-6108
}

Additional index words. cold acclimation, woody plants, supercooling, nonsupercooling, freezing response

\begin{abstract}
Temperate woody plants have evolved two methods for coping with seasonal exposure to subzero temperatures. Supercooling is a freeze-avoidance strategy in which cells can avoid intracellular freezing below subzero temperatures. Nonsupercooling is a freeze-tolerance strategy in which the growth of extracellular ice crystals is promoted and intracellular water is withdrawn. Thus, nonsupercooling species have also evolved adaptations to tolerate intracellular dehydration, which results from the formation of extracellular ice. The goal of our study was to provide the first broad characterization of freezing response within two representative woody genera (Acer and Betula) in relation to the evolution of the freezing response trait. Although all of the examined Acer species (nine) exhibited xylem supercooling response, only five of 14 Betula species were identified as supercooling species. When the characterized freezing responses were overlaid onto a phylogenetic tree, the supercooling freezing response was revealed as an ancestral trait in Betula.
\end{abstract}

In nature, temperature acts as a selective pressure for plant growth and has limited the geographical distribution of many species (Becwar et al., 1981; George et al., 1974; Gray et al., 1997; Gusta et al., 1983; Linden et al., 1999; Sakai and Weiser, 1973; Smithberg and Weiser, 1968; Thomashow, 1999). In response to varying seasonal temperatures within temperate climates, plants have evolved the ability to survive when exposed to subzero temperatures through a process known as cold acclimation. In temperate woody plants, a first stage of cold acclimation is typically triggered in response to the

Received for publication 6 Oct. 2009. Accepted for publication 16 Nov. 2009

We acknowledge the Arnold Arboretum for their generous donation of woody plant material used for this study. We would thank Kyle Port (Arnold Arboretum) who assisted in the collection and shipment of the plant material. We thank Bill Anger (USDA-ARS, Kearneysville, WV) for his assistance with the setup and analysis of data obtained by differential thermal analysis. West Virginia Agriculture and Forestry Experiment Station Scientific Article No. 3056.

${ }^{1}$ Current address: Monsanto Company, Abiotic Stress Physiology, 110 TW Alexander Drive, Research Triangle Park, NC 27709.

${ }^{2}$ To whom reprint requests should be addressed; e-maildale.karlson@monsanto.com. seasonal decrease in day length (Fuchigami et al., 1971; Howell and Weiser, 1970; Hurst et al., 1967; Irving and Lanphear, 1967; Malone and Ashworth, 1991b; McKenzie et al., 1974; VanHuystee et al., 1967; Weiser, 1970). A second stage of cold acclimation triggered by exposure to low temperature was initially documented in Cornus sericea (VanHuystee et al., 1967; Weiser, 1970) and is recognized to occur in many freeze-tolerant temperate woody plants ( $\mathrm{Li}$ et al., 2003; Welling et al., 2002, 2004; Wisniewski et al., 2003).

Woody plants evolved two freezing responses for surviving prolonged exposure to subzero temperatures: freeze tolerance (nonsupercooling) and freezing avoidance (deep supercooling) (Burke et al., 1976; George et al., 1982). In nonsupercooling cells, ice formation is initiated in extracellular spaces and intracellular water is withdrawn to the extracellular ice crystals resulting from the presence of a vapor pressure gradient (Burke et al., 1976; Guy, 1990; Levitt, 1980; Ristic and Ashworth, 1994). Thus, nonsupercooling cells are exposed to freeze-induced dehydration and tolerant species are capable of surviving this stress in a cold-acclimated state (Ashworth et al., 1993; Fujikawa et al., 1997; Wisniewski and Arora, 2000; Wisniewski et al., 2003).

Deep supercooling is the second freezing response that is characterized by the ability of woody plants to resist the formation of intracellular ice below subzero temperatures. However, in contrast to nonsupercooling cells, hardiness or survival is typically limited to the homogenous ice nucleation temperature $\left(-40{ }^{\circ} \mathrm{C}\right)$ of water (Rasmussen and MacKenzie, 1972). As a result of this inherent limitation of deep supercooling, the geographical distribution of woody plants has been extensively studied in relation to freezing response (Becwar et al., 1981; George et al., 1974; Sakai and Weiser, 1973; Smithberg and Weiser, 1968).

In general, deep supercooling plants are restricted in geographical range to areas that do not fall below $-40{ }^{\circ} \mathrm{C}$ (George et al., 1974). Because this temperature coincides with the homogenous nucleation temperature of water, plant species exhibiting deep supercooling are limited in their ability to survive temperatures below $-40{ }^{\circ} \mathrm{C}$, although exceptions to this restraint have been documented (Gusta et al., 1983). At this temperature, the spontaneous nucleation of intracellular supercooled water can occur, resulting in cellular death (Burke et al., 1976). In contrast, no discrete lower temperature limit exists for the survival of freeze-tolerant, nonsupercooling woody plants. Instead, the ability of nonsupercooling woody plants to survive winter is primarily limited by their capacity to withstand the intracellular dehydration that is induced by formation of extracellular ice crystals at low temperatures (Ashworth et al., 1993; Burke et al., 1976; Fujikawa et al., 1997). Thus, the geographical ranges of nonsupercooling species may extend to northernmost regions with annual temperatures that are substantially colder than the $-40{ }^{\circ} \mathrm{C}$ isotherm (George et al., 1974). In the Cornus genus, $C$. florida and $C$. sericea differ in their xylem freezing response and highlight differences in geographical range that are based on their mechanisms of cold-hardiness (Karlson et al., 2004). Although the northern distribution of $C$. florida is limited to regions warmer than $-40{ }^{\circ} \mathrm{C}, \mathrm{C}$. sericea is unrestricted in its northernly distribution. Under controlled conditions, $C$. sericea has been shown to exhibit extreme freeze tolerance and can survive exposure in liquid helium (Guy et al., 1986). Geographical distribution of other species linked to freezing response has also been documented (George et al., 1974).

A previous interspecific study within Cornus (dogwoods) investigated xylem freezing response and determined that the majority of Cornus species exhibit deep supercooling (Karlson et al., 2004). In that study, a phylogenetic analysis of Cornus indicated that nonsupercooling (freezing tolerance) arose in the most recently divergent group of dogwoods as a late evolutionary event and this may have facilitated the expansion of nosupercooling species into northern ranges (Karlson et al., 2004). Because similar interspecific studies are lacking in other woody species, the purpose of this study was to characterize the freezing response in a range of species within two temperate woody genera. By determining the freezing response of 
Betula and Acer species, we have demonstrated that the majority of Betula species are nonsupercooling, whereas Acer species are predominantly supercooling. From this current study, these data from two additional woody plant genera add support to the previously established hypothesis that xylem supercooling freezing response is an ancestral trait (Karlson et al., 2004) in multiple temperate woody genera.

\section{Materials and Methods}

Plant material. Stems from current-year growth were randomly collected from Betula and Acer species growing at the Arnold Arboretum, Harvard University (Dec. 2005). Accession numbers for plant samples are listed in Table 1. An additional birch species (Betula maximowicziana) specimen was collected in Mar. 2007. Cut branches were immediately wrapped in damp paper towels on collection, sealed in plastic bags, packed on ice, and shipped overnight to the USDA-ARS Appalachian Fruit Research Center, Kearneysville, WV, for differential thermal analysis (DTA). On arrival to the research center, all samples were maintained at $4{ }^{\circ} \mathrm{C}$ until at least three DTA replicates were completed for each species.

Differential thermal analysis. DTA was performed to categorize xylem freezing into either supercooling or nonsupercooling responses as previously described (Karlson et al., 2004; Malone and Ashworth, 1991a; Wisniewski and Davis, 1989; Wisniewski et al., 1991a, 1991b). Briefly, bark was removed from current-year stems with a scalpel and a $1-\mathrm{cm}$ internodal stem cross-section was harvested. A 40-gauge copper/constantan thermocouple was attached to the debarked stem section with parafilm. Stem sections were subsequently placed into a test tube and lowered into a predrilled aluminum block that was housed in a $-80{ }^{\circ} \mathrm{C}$ freezer. The block temperature was controlled by resistance heating and monitored with an Omega CN-2010 programmable temperature controller (Stamford, CT). Samples were equilibrated at $5{ }^{\circ} \mathrm{C}$ for $30 \mathrm{~min}$. The temperature was then lowered from $5{ }^{\circ} \mathrm{C}$ to $-45{ }^{\circ} \mathrm{C}$ at $20^{\circ} \mathrm{C} / \mathrm{h}$. Several of our previous studies have shown that slower cooling rates have no impact on the freezing profiles of the samples (Wisniewski, 1995). Low-temperature exotherms were measured by comparing the differential output of samples to an ovendried, internodal section of current-year stem tissue (bark removed), which served as a reference. A minimum of three replicate differential analyses was performed for each species and freezing responses were categorized into either supercooling or nonsupercooling by the presence or absence of a low-temperature exotherm (LTE), respectively.

\section{Results and Discussion}

Characterization of xylem freezing response within Acer species. Xylem freezing response was characterized for nine Acer species. All Acer species exhibited LTEs, which is the key indicator for the supercooling response, and were thus categorized as supercooling species (Table 1). Although all Acer species showed LTEs, the temperature span of these exotherms (temperature range from initiation to termination of LTE) as well as the temperatures at which they initiated varied between species (see Table 1, Fig. 1). Specifically, A. rubrum and A. spicatum exhibited relatively narrow LTE peaks, which extended for a range of $\approx 8$ to $9^{\circ} \mathrm{C}$ ( see

Table 1; Fig. 1). Conversely, the additional seven Acer species exhibited broader peaks, which spanned a temperature range greater than $16{ }^{\circ} \mathrm{C}$ (see Table 1; Fig. 1). Acer rubrum and A. spicatum also showed LTEs, which initiated at the lowest temperatures, $\approx-37^{\circ} \mathrm{C}$ (Table 1). In contrast, the remainder of the Acer species showed LTEs, which initiated at considerably warmer temperatures (Table 1). Specifically, the average LTEs for $A$. carpinofolium, A. cissifolium, A. davidii, A. griseum, A. platanoides, $A$. pseudoplatanus, and

Table 1. List of plant material and characterization of freezing responses within Acer and Betula species.

\begin{tabular}{lcccc}
\hline Specimen & $\begin{array}{c}\text { Freezing } \\
\text { behavior }\end{array}$ & $\begin{array}{c}\text { LTE initiation } \\
\left({ }^{\circ} \mathrm{C}\right)\end{array}$ & $\begin{array}{c}\text { LTE span } \\
\left({ }^{\circ} \mathrm{C}\right)\end{array}$ & Accession \\
\hline A. carpinofolium & $\mathrm{S}$ & $-20.4 \pm 0.3$ & $22.0 \pm 0.7$ & 10959 \\
A. cissifolium & $\mathrm{S}$ & $-23.5 \pm 1.3$ & $17.7 \pm 2.0$ & 10649 \\
A. davidii & $\mathrm{S}$ & $-22.4 \pm 0.5$ & $18.0 \pm 0.9$ & $126-2003$ \\
A. griseum & $\mathrm{S}$ & $-20.1 \pm 0.2$ & $20.7 \pm 0.9$ & 12488 \\
A. platanoides & $\mathrm{S}$ & $-26.5 \pm 0.3$ & $16.2 \pm 0.5$ & 12543 \\
A. pseudoplatanus & $\mathrm{S}$ & $-20.3 \pm 1.0$ & $20.6 \pm 1.3$ & $77-2005$ \\
A. rubrum & $\mathrm{S}$ & $-38.9 \pm 0.6$ & $7.7 \pm 0.3$ & $875-93$ \\
A. spicatum & $\mathrm{S}$ & $-36.3 \pm 2.0$ & $9.2 \pm 3.9$ & $359-79$ \\
A. tataricum & $\mathrm{S}$ & $-18.9 \pm 1.4$ & $26.1 \pm 2.8$ & $78-2000$ \\
B. albo-sinensis & $\mathrm{N}$ & & & $358-2001$ \\
B. apoiensis & $\mathrm{N}$ & & & $68-92$ \\
B. chichibuensis & $\mathrm{S}$ & $-12.2 \pm 0.1$ & $9.3 \pm 0.9$ & $389-93$ \\
B. costata & $\mathrm{N}$ & & & $373-97$ \\
B. davurica & $\mathrm{S}$ & $-14.7 \pm 0.1$ & $8.6 \pm 2.0$ & $1015-80$ \\
B. globispica & $\mathrm{N}$ & & & $10-88$ \\
B. lenta & $\mathrm{S}$ & $-39.0 \pm 0.6$ & $9.1 \pm 0.3$ & 17679 \\
B. maximowicziana & $\mathrm{S}$ & $-13.4 \pm 0.8$ & $9.3 \pm 0.9$ & $16-98$ \\
B. nigra & $\mathrm{N}$ & & & 1199 \\
B. papyrifera & $\mathrm{N}$ & & & $142-85$ \\
B. pendula & $\mathrm{N}$ & & & $1299-79$ \\
B. populifolia & $\mathrm{N}$ & & & $1536-83$ \\
B. pubescens & $\mathrm{N}$ & & $5.0 \pm 1.0$ & $253-93$ \\
B. schmidtii & $\mathrm{S}$ & $-38.7 \pm 0.1$ & \\
\hline A & & & & 258 \\
\hline
\end{tabular}

Accession numbers for each species are respectively listed. Differential thermal analysis conducted to categorize xylem freezing responses in all species into either supercooling $(\mathrm{S})$ or nonsupercooling $(\mathrm{N})$. For supercooling species, the temperatures at which their low temperature exotherms (LTEs) initiated are listed. The range of the LTEs (temperature span from initiation to termination of LTEs) is also listed.
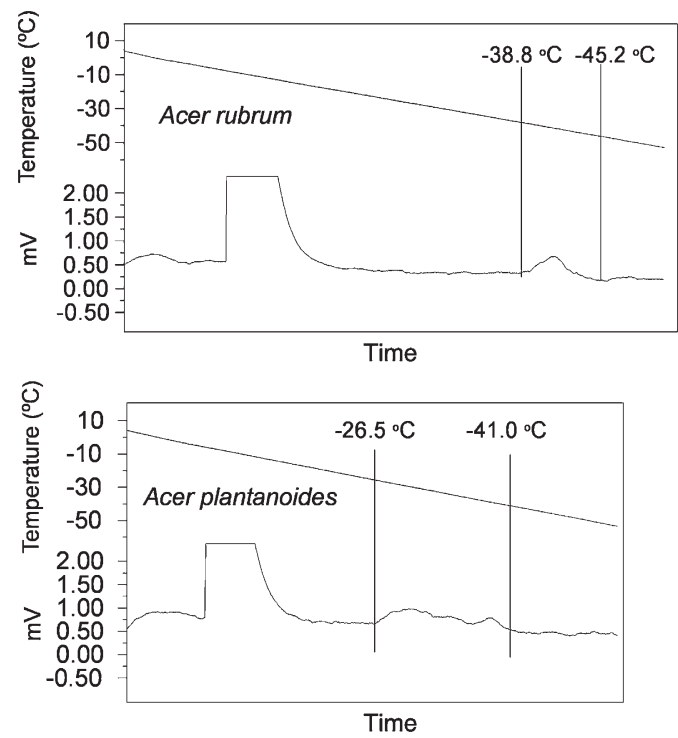

Fig. 1. Low-temperature exotherm (LTE) plots for two representative Acer species. LTEs varied greatly between species in their temperature spans from the initiation and termination of LTEs. Acer rubrum exhibited a relatively narrow LTE temperature span, whereas Acer platanoides exhibited a relatively broad LTE temperature span. LTEs also differed between species where some exhibited unimodal (i.e., Acer rubrum) or bimodal (i.e., Acer platanoides) LTE peaks. 
A. tataricum all initiated between -18.9 and $-26.5{ }^{\circ} \mathrm{C}$. Interspecific differences were also observed in the number of detected LTE peaks among the Acer species. Specifically, A. cissifolium, A. davidii, A. griseum, A. platanoides, $A$. pseudoplatanus, and $A$. tataricum all displayed bimodal peaks, whereas $A$. carpinofolium, A. rubrum, and A. spicatum displayed a single peak (see Fig. 1).

Characterization of xylem freezing response within Betula species. In Cornus, both supercooling and nonsupercooling responses to freezing have been observed. In a previous study, deep supercooling appeared to be a derived trait suggesting differential evolution of the freezing response in the Cornus genus (Karlson et al., 2004). The present study indicates a similar pattern in Betula with nine of 14 tested species exhibiting a nonsupercooling freezing response.

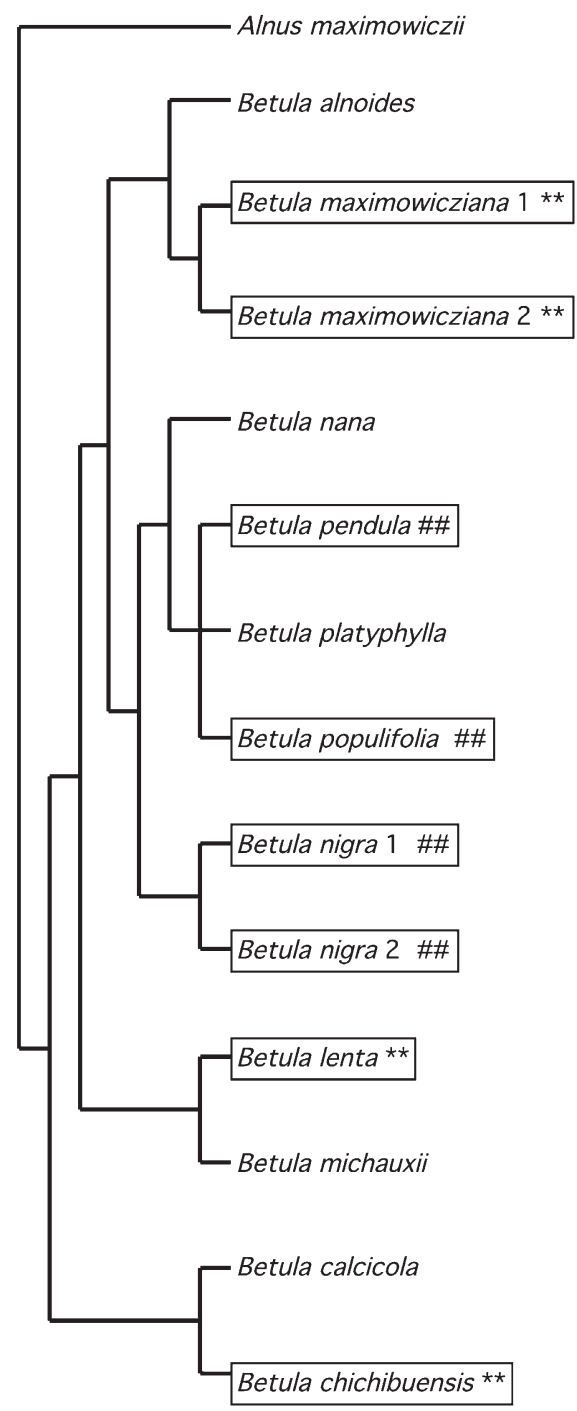

Fig. 2. Phylogenetic analysis of xylem freezing responses in Betula. Physiological data regarding the freezing response trait were overlaid on a previously generated molecular phylogeny. Supercooling species (boxes with **) were found exclusively in early divergent clades of birch, whereas nonsupercooling species (boxes with \#\#) were found in the most recently divergent clades of birch.
These data sharply contrast the results obtained from the Acer genus in which all of the species exhibited a supercooling freezing response in xylem tissue (Table 1). Unlike the bimodal LTE profiles that were obtained from supercooling species of Acer, all supercooling Betula species exhibited a single LTE peak.

In contrast to the Acer supercooling species, the majority of nonsupercooling Betula species occupy regions with colder climates as classified by their respective hardiness zone designations from the following references: Manual of Woody Landscape Plants (Dirr, 1998), Complete Encyclopedia of Trees and Shrubs (Wasson, 2003), and Index of Garden Plants (Griffiths, 1994). Specifically, six of the nine nonsupercooling species (B. costata, B. globispica, B. papyrifera, B. pendula, $B$. populifolia, and $B$. pubescens) extend into ranges beyond the $-40{ }^{\circ} \mathrm{C}$ isotherm (data not shown). Collectively, these data support the established findings that nonsupercooling species are capable of extending into more northern geographies in comparison with supercooling species (Becwar et al., 1981; George et al., 1974; Sakai and Weiser, 1973; Smithberg and Weiser, 1968). These findings also add support to a previous hypothesis that the evolution of the nonsupercooling freezing response trait may have facilitated the expansion of some woody genera, whose ancestors exhibited supercooling, into colder climates (Karlson et al., 2004).

Phylogenetic analysis of the freezing response trait in Betula. Because both nonsupercooling and supercooling freezing responses were observed within Betula, we were interested to characterize the evolutionary trend for this trait. Therefore, we overlaid our freezing response data onto a previously generated phylogenetic tree ( $\mathrm{Li}$ et al., 2007), which contained six of the 14 species used in our study (Fig. 2). In this tree, all supercooling species were found within early divergent clades of birch, whereas nonsupercooling species were only found in the most recently divergent clades.

Although deep supercooling was recognized as a heritable trait that can be eliminated by selection many years ago (Burke and Stushnoff, 1979), the evolution of freezing behavior in temperate woody plants has only recently been characterized (Karlson et al., 2004). When mapped onto a phylogenetic tree of diploid species of Betula ( $\mathrm{Li}$ et al., 2007), freezing response shows an evolutionary trend from supercooling to nonsupercooling (Fig. 2) as previously observed in Cornus (Karlson et al., 2004). In the present study, our characterization of the evolution of freezing response in a second temperate woody plant genus indicates that the ancestral supercooling trait may be a common evolutionary feature shared by multiple woody plant genera. In the future, assemblage of a comprehensive phylogenetic tree of Betula species would enable estimation for the timing of the evolution of nonsupercooling response and provide clues for the poten- tial connection of freezing response with the onset of the last maximum glaciation.

\section{Literature Cited}

Ashworth, E.N., S.R. Malone, and Z. Ristic. 1993. Response of woody plant cells to dehydrative stress. Intl. J. Plant Sci. 154:90-99.

Becwar, M.R., C. Rajashekar, K.J.H. Bristow, and M.J. Burke. 1981. Deep undercooling of tissue water and winter hardiness limitations in timberline flora [Picea engelmannii, Abies lasiocarpa]. Plant Physiol. 68:111-114.

Burke, M.J. and C. Stushnoff. 1979. Frost hardiness: A discussion of possible molecular causes of injury with particular reference to deep supercooling of water, p. 199-225. In: Mussell, H. and R.C. Staples (eds.). Stress physiology of crop plants. Wiley, New York, NY.

Burke, M.J., L.V. Gusta, H.A. Quamme, C.J. Weiser and P.H. Li. 1976. Freezing and injury in plants. Annu. Rev. Plant Physiol. 27:507528.

Dirr, M.A. 1998. Manual of woody landscape plants. Stipes Publishing, Champaign, IL.

Fuchigami, L.H., C.J. Weiser, and D.R. Evert. 1971. Induction of cold acclimation in Cornus stolonifera Michx. Plant Physiol. 47:98-103.

Fujikawa, S., K. Kuroda, and J. Ohtani. 1997. Seasonal changes in dehydration tolerance of xylem ray parenchyma cells of Stylax obassia twigs that survive freezing temperatures by deep supercooling [Erratum: 1997;198:231]. Protoplasma 197:34-44.

George, M.F., M.R. Becwar, and M.J. Burke. 1982. Freezing avoidance by deep undercooling of tissue water in winter-hardy plants. Cryobiology 19:628-639.

George, M.F., M.J. Burke, H.M. Pellet, and A.G. Johnson. 1974. Low temperature exotherms and woody plant distribution. HortScience 9:519-522.

Gray, G.R., L.P. Chauvin, F. Sarhan, and N. Huner. 1997. Cold acclimation and freezing tolerance (a complex interaction of light and temperature). Plant Physiol. 114:467-474.

Griffiths, M. 1994. Index of garden plants. Macmillan Press, London, UK.

Gusta, L.V., N.J. Tyler, and T. Chen. 1983. Deep undercooling in woody taxa growing north of the $-40^{\circ} \mathrm{C}$ isotherm. Plant Physiol. 72:122-128.

Guy, C.L. 1990. Cold acclimation and freezing stress tolerance: Role of protein metabolism. Annu. Rev. Plant Physiol. Plant Mol. Biol. 41:187-223.

Guy, C.L., K.J. Niemi, A. Fennell, and J.V. Carter. 1986. Survival of Cornus sericea L. stem cortical cells following immersion in liquid helium. Plant Cell Environ. 9:447-450.

Howell, G.S. and C.J. Weiser. 1970. The environmental control of cold acclimation in apple. Plant Physiol. 45:390-394.

Hurst, C., T.C. Hall, and C.J. Weiser. 1967. Reception of the light stimulus for cold acclimation in Cornus stolonifera Michx. HortScience 2:164-166.

Irving, R.M. and F.O. Lanphear. 1967. Environmental control of hardiness in woody plants. Plant Physiol. 42:1191-1196.

Karlson, D.T., Q.Y. Xiang, V.E. Stirm, A.M. Shirazi, and E.N. Ashworth. 2004. Phylogenetic analyses in Cornus substantiate ancestry of xylem supercooling freezing behavior and reveal lineage of desiccation related proteins. Plant Physiol. 135:1654-1665.

Levitt, J. 1980. Responses of plants to environmental stresses. Chilling, freezing, and high 
temperature stresses. Vol. 1. Academic Press, New York, NY.

Li, C.Y., O. Junttila, A. Ernstsen, P. Heino, and E.T. Palva. 2003. Photoperiodic control of growth, cold acclimation and dormancy development in silver birch (Betula pendula) ecotypes. Physiol. Plant. 117:206-212.

Li, J.H., S. Shoup, and Z.D. Chen. 2007. Phylogenetic relationships of diploid species of Betula (Betulaceae) inferred from DNA sequences of nuclear nitrate reductase. Syst. Bot. 32:357365.

Linden, L., P. Palonen, and M. Seppanen. 1999. Cold hardiness research on agricultural and horticultural crops in Finland. Agricultural and Food Science in Finland 8:459-477.

Malone, S.R. and E.N. Ashworth. 1991a. Freezing stress response in woody tissues observed using low-temperature scanning electron microscopy and freeze substitution techniques. Plant Physiol. 95:871-881.

Malone, S.R. and E.N. Ashworth. 1991b. Freezing stress response in woody tissues observed using low-temperature scanning electron microscopy and freeze substitution techniques. Plant Physiol. 95:871-881.

McKenzie, J.S., C.J. Weiser, and M.J. Burke. 1974. Effects of red and far red light on the initiation of cold acclimation in Cornus stolonifera Michx. Plant Physiol. 53:783-789.

Rasmussen, D.H. and A.P. MacKenzie. 1972. Effect of solute on ice solution interfacial free energy; calculation from measured homogenous nucleation temperatures, p. 126-145. In:
Jellinek, H.H.G. (ed.). Water structure at the water-polymer interface. Plenum Publishing Co., New York, NY.

Ristic, Z. and E.N. Ashworth. 1994. Response of xylem ray parenchyma cells of red osier dogwood (Cornus sericea L.) to freezing stress. Microscopic evidence of protoplasm contraction. Plant Physiol. 104:737-746.

Sakai, A. and C.J. Weiser. 1973. Freezing resistance of trees in North America with reference to tree regions. Ecology 54:118-126.

Smithberg, M. and C. Weiser. 1968. Patterns of variation among climatic races of red-osier dogwood. Ecology 49:495-505.

Smithberg, M.H.W. and C.J. Weiser. 1968. Patterns of variation among climatic races of redosier dogwood. Ecology 49:495-505.

Thomashow, M.F. 1999. Plant cold acclimation: Freezing tolerance genes and regulatory mechanisms. Annu. Rev. Plant Physiol. Plant Mol. Biol. 50:571-599.

VanHuystee, R.B., C.J. Weiser, and P.H. Li. 1967. Cold acclimation in Cornus stolonifera under natural and controlled photoperiod and temperature. Bot. Gaz. 128:200-205.

Wasson, E. 2003. The complete encyclopedia of trees and shrubs. Thunder Bay Press, San Diego, CA.

Weiser, C.J. 1970. Cold resistance and injury in woody plants. Science 169:1269-1278.

Welling, A., T. Moritz, E.T. Palva, and O. Junttila. 2002. Independent activation of cold acclimation by low temperature and short photoperiod in hybrid aspen. Plant Physiol. 129:1633-1641.
Welling, A., P. Rinne, A. Vihera-Aarnio, S. Kontunen-Soppela, P. Heino, and E.T. Palva. 2004. Photoperiod and temperature differentially regulate the expression of two dehydrin genes during overwintering of birch (Betula pubescens Ehrh.). J. Expt. Bot. 55:507-516.

Wisniewski, M. 1995. Deep supercooling in woody plants and the role of cell wall structure, p. 163182. In: Lee, R.E., G.J. Warren, and L.V. Gusta (eds.). Biological ice nucleation and its applications. APS Press, St. Paul, MN.

Wisniewski, M. and R. Arora. 2000. Structural and biochemical aspects of cold acclimation in woody plants, p. 419-437. In: Jain, S.M. and S.C. Minocha (eds.). Molecular biology of woody plants. Kluwer Academic, Dordrecht, The Netherlands.

Wisniewski, M., C. Bassett, and L.V. Gusta. 2003. An overview of cold hardiness in Woody plants: Seeing the forest through the trees. HortScience 38:952-959.

Wisniewski, M. and G. Davis. 1989. Evidence for the involvement of a specific cell-wall layer in regulation of deep supercooling of xylem parenchyma. Plant Physiol. 91:151-156.

Wisniewski, M., G. Davis, and R. Arora. 1991a. Effect of macerase, oxalic-acid, and EGTA on deep supercooling and pit membrane-structure of xylem parenchyma of peach. Plant Physiol. 96:1354-1359.

Wisniewski, M., G. Davis, and K. Schaffer. 1991b. Mediation of deep supercooling of peach and dogwood by enzymatic modifications in cellwall structure. Planta 184:254-260. 